\title{
USING A NEW SUPPLY CHAIN PLANNING METHODOLOGY TO IMPROVE SUPPLY CHAIN EFFICIENCY
}

\author{
A.L.V. Raubenheimer and P.J. Conradie \\ Department of Industrial and Systems Engineering \\ University of Pretoria \\ pconradi@postino.up.ac.za
}

\begin{abstract}
Effective supply chain planning and management has emerged as one of the most challenging opportunities for companies in the global economy during the last decade or two. This article reviews the evolution of Supply Chain Management and the traditional Supply Chain Solutions. It then introduces a new Supply Chain Planning methodology in which simulation modelling plays an important value-adding role to help organisations understand the dynamics of their Supply Chains.
\end{abstract}

\section{OPSOMMING}

Effektiewe voorsieningskettingbeplanning en -bestuur het gedurende die laaste twee dekades ontwikkel tot een van die mees uitdagende geleenthede vir ondernemings in die wêreldekonomie. Hierdie artikel hersien kortliks die ontwikkeling van voorsieningskettingbestuur en die tradisionele oplossings. 'n Nuwe voorsieningskettingbeplanningsmetodologie word dan voorgestel en bespreek waarin simulasiemodellering ' $n$ belangrike rol speel om ondernemings te help om die dinamika van hul voorsieningskettings te begryp. 


\section{INTRODUCTION}

As globalisation increases businesses are confronted with new strategies to improve their operational excellence, customer relations and supply chain integration. Supply Chain Integration is one of the areas that can have a great impact on the financial statements of a company and customer satisfaction.

Due to this intensified focus on supply chain integration companies have invested millions of dollars over the last couple of years in supply chain planning and execution systems. Companies want to develop systems that enable them to deliver the right products to the right customers at the right time, with the necessary flexibility, speed, visibility and quality.

The biggest obstacles in this objective are the uncertainty and interdependency of processes within a supply chain. The need arise for companies to implement strategies or methodologies that can give insight into the uncertainty and interdependency of processes. In order to achieve a competitive advantage in the global market place, new strategies or methodologies need to be evaluated.

This article focuses on the evolution of supply chain management, concentrating on the concepts and technologies of Supply Chain Solutions. As the concepts are discussed, it will be pointed out why it is necessary to increase the efficiency of supply chain planning. The foundation will be laid to introduce a new Supply Chain Planning Methodology, which will then be discussed in detail.

\section{EVOLUTION OF SUPPLY CHAIN MANAGEMENT}

\subsection{Introduction}

Throughout the history of mankind a lot of wars have been won and lost through logistics strengths and capabilities and ironically Generals and Field Marshals were the ones who understood the critical role of logistics long before it was clearly defined. One of the first warnings of how complex logistics could be, emerged as early as 1915 when Arch Shaw [1] wrote the following:

" The relations between the activities of demand creation and physical supply... illustrate the existence of the two principles of inter-dependence and balance. Failure to co-ordinate any one of these activities with its group fellows and also with those in the other group, or undue emphasis or outlay put upon any one of these activities, is certain to upset the equilibrium of forces which means efficient distribution.

The physical distribution of the goods is a problem distinct from the creation of demand... Not a few worthy failures in distribution campaigns have been due to such a lack of coordination between demand creation and physical supply...Instead of being a subsequent problem, this question of supply must be met and answered before the work of distribution begins."

However, it took a further 70 or so years before the basic principles of logistics management were clearly defined. One of the first definitions came from Martin Christopher [2] and he 
defined logistics as follows:

" Logistics is the process of strategically managing the procurement, movement and storage of materials, parts and finished inventory (and related information flows) through the organisation and its marketing channels in such a way that current and future profitability are maximised through the cost-effective fulfilment of orders."

Through the 90's organisations started to realise that their traditional approach to planning no longer provided them with a competitive advantage. Furthermore, it was evident that in order to reengineer the planning process one would need to "overhaul" one's traditional process into an innovative approach, an approach that is integrated across multiple dimensions where material and capacity planning is integrated into one problem and where production and distribution are also integrated.

It was important that the new approach provided one with the necessary flexibility, speed, visibility and quality and that the planning should not be done on islands, but must be integrated into one single funnel with the detail varying over a combined horizon. All of these efforts and thoughts paved the way for an opportunity that would solve the need to truly integrate one's processes.

It was further believed that this new approach would no longer allow excess inventory, unused capacity, missed due dates or even unsynchronised distribution plans and that this solution will eventually sort out the conflicting objectives between manufacturing, sales and distribution functions.

The opportunity was called Supply Chain Management. Archibald [3] defines it as achieving a sustainable competitive advantage, maximizing shareholder value and optimising the relationship of process, information, and physical goods among internal and external trading partners. Exploiting this opportunity is a challenge one dare not even think of not accepting.

Managing one's Supply Chain is quite a complex task. One needs $\mathbf{b}$ move and rearrange all the assets in such a way so that the "stakeholders", customers, shareholders, employees, unions and regulators, are satisfied.

During the years businesses have tried to deal with the problem by breaking it down into pieces, rigging up walls between different segments of the chain, which fragmented the responsibilities in different segments in the chain. In order to cope with these pieces, businesses used different tools to track these islands of data. Because of the fragmentation there is no integration and one does not have the ability to see the "bigger picture" of what the effect of different decisions and actions is on the total supply chain and the bottom line.

Without the necessary visibility, decision-making is a slow and arduous task. In today's highly competitive market businesses need to have the ability to make informal decisions rapidly, so responsiveness is one of the key measurements. The faster businesses can respond to their customer needs, the better.

In other words businesses need something more than just a localised view - one need to be able to have visibility on a global scale. This means that traditional business systems are not 
the solution any more, because the assumptions have changed. Businesses no longer can afford to only view parts of the business puzzle; they need to see the whole puzzle.

\subsection{Supply Chain Solutions}

Today there is a typical core methodology for each type of problem within the supply chain, which are better known as "solver technologies". Examples of the solver technologies that provide the results or outputs of the advanced planning and scheduling tools are:

- $\quad$ Heuristics

- Constraint Management

- Linear Programming

- $\quad$ Mixed Integer Programming

- $\quad$ Network Programming

Over the years it was proved that companies which followed a classical approach to logistics was more vulnerable to change than the ones that didn't. The only real method of demonstrating this vulnerability to poor management of change is through models in which the techniques of systems dynamics are applied to the industrial environment.

Companies generally increase their vulnerability themselves by inducing unreal business cycles and even further amplify them by localised protective policies. According to John B. Houlihan [4], a company's vulnerability can be considered in a dual context - the context of its external placement in a global supply chain and the context of its internal supply systems. In the case of placement within the global supply chain, the further a company is from its end users of its products, the greater are the demand swings. The effects experienced by such a company are the cumulative results of time delays, planning distortions and inventory shakeups in preceding links of the chain.

In the last couple of years some Supply Chain Solution providers emerged that introduced tools with the ability to rapidly and simultaneously plan and schedule customer demand, while considering materials and capacity constraints. They provide the ability to increase revenues, improve customer service and cut costs by synchronised management of the complete supply chain. Some of these players are listed in the Supply Chain Magic Quadrant Update generated by the Gartner Group [5]. (See Figure 1.) 


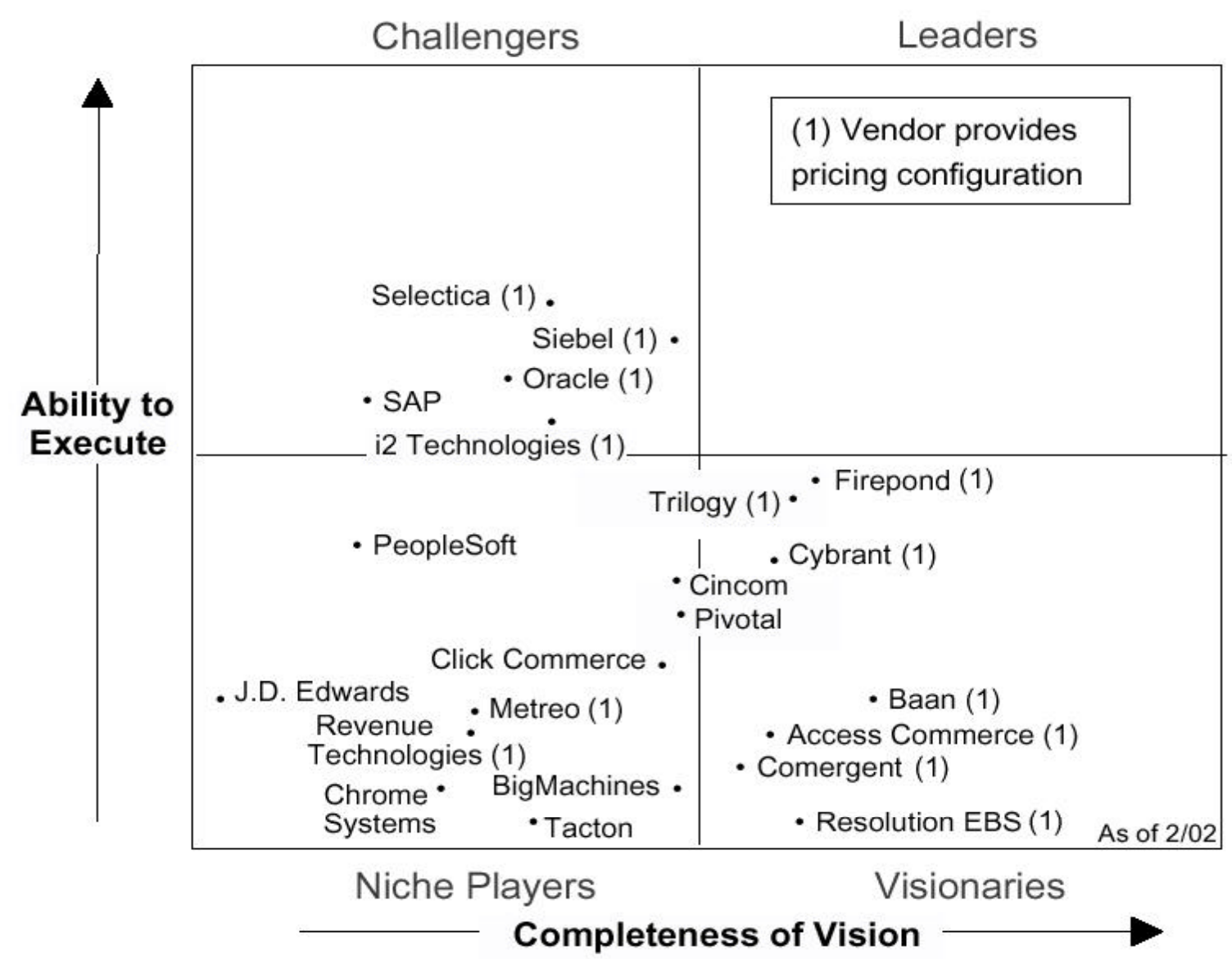

Figure 1: Supply Chain Magic Quadrant Update [5]

There are currently no vendors in the leaders quadrant, because no vendor has 20 production references that meet the majority requirements. The Supply Chain Solution tool's function is to find the interdependency of the system constraints that minimises cost and maximises profit.

Within these tools exist a "Critical Path" and a "Shortest Path", that achieve the min/max idea while looking at the variability behind production allocation, expansion, consolidation and resource planning. But the question that one should ask now is whether there exists only one answer to the problems? The only way that one can ensure one optimal answer is when the demand is constant and there is a zero percent probability that it could change.

In real world systems it is virtually impossible to accurately predict future demand 100 percent of the time, and therefore variability and randomness cannot be excluded from a supply chain solution. However, these systems, although powerful, are still working with static data and therefore do not take the randomness and dynamic variability of the entire supply chain into account. Experimentation is performed on the live business, therefore increasing an organisation's vulnerability. With a Supply chain planning system in place it is relatively easy to change global inventory settings, but the new setting will also just be a set of static parameters. 
Visibility is still limited in some key issues, which lead to companies treating the effects and not the cause, wasting limited resources and therefore only achieving incremental improvements, and investing inappropriately.

What becomes clear is that when considering a supply chain solution, the solution needs to include randomness and variability, which will provide the dynamic capabilities to the planning function. The technology that is able to provide this randomness and variability is dynamic, discrete-event simulation.

Simulation (discrete event) is defined by Ted Matwijec [6] as follows: "creating a computer model of a real or proposed system and conducting experiments on the model to describe observed behaviour and/or predict future behaviour before investing any time or money". Because experimenting on a real system could be costly and/or impractical, simulation has become an extremely important tool for designing and analysing complex systems; it is a cost-effective way of testing proposed systems, plans, or policies before incurring the expense of prototypes, failed tests, or actual explanations.

Simulation, however, is not a "solver technology" - it is a methodology to evaluate detailed solutions and alternatives in the supply chain.

\section{CONCEPTS OF SIMULATION}

As Kelton [7] puts it, "simulation is the process of designing and creating a computerised model of a real or proposed system for the purpose of conducting numerical experiments to give analysts a better understanding of the behaviour of that system for a given set of conditions. Simulation is often used to study fairly simple systems, but the real power of this method can only be realised and appreciated when analysing complex systems".

Many analysts will argue that simulation is not the only tool that can be used to evaluate these systems, but why is it frequently the method of choice? The answer to this is that simulation allows the analyst to represent the system faithfully and to the finest detail, thus capturing the complexity of the system with the added ability of what-if analysis into one model. Other systems on the other hand may require stronger simplifying assumptions about the system to enable analysis, therefore questioning the validity of the model. Add to this the animation capabilities of modern simulation software and it becomes clear why many users prefer simulation.

\subsection{So, why use Simulation in Supply Chain Planning?}

Simulation can certainly be an insurance policy in change management and can capture the randomness of systems. Simulation can model the corporate dynamics in the complete supply chain, from source to the end user through the Plan, Source, Make, and Deliver processes, enabling the analyst to model the "bigger picture".

Variability is mainly a function of the statistical nature of simulation tools. The output from a simulation model is not only statistical data, but it also consists of performance animation through which the system dynamics can be viewed. Simulation can reliably capture and predict the effect of multiple changes in corporate systems. Supply Chain Management is 
difficult and the key to any supply chain performance is to understand the variability of the processes of the system. Simulation gives companies a visual presentation of their systems performance and provides the ability to "test drive" the system before it is implemented.

When researching the internal, as well as the external environmental conditions that most companies face today, it is found that they are experiencing one or more of the following conditions:

- Constantly changing operations - (production line, factory, warehouse, distribution systems opening/closing/expanding/contracting)

- $\quad$ Mergers, acquisitions or joint vendors

- Information systems changing/merging

- Increasing competition

- Increasing customer expectations

- Demand for higher profits

- Complex systems integration

- $\quad$ Conflicting management objectives - centralise, decentralise

- $\quad$ Automation and outsourcing needs

- Mass customisation pressures

- $\quad$ Changing inventory policies.

All the items mentioned above clearly affect the efficiency with which a supply chain functions. Simulation can help companies to gain knowledge of the system dynamics by making better evaluations (test-drive or perform "what-if" analyses) of the supply chain in order to improve the performance. When conducting a simulation project it forces companies to re-evaluate their way of thinking, and their understanding of system operations and thus defines the system clearly. It therefore minimises multiple (mis)interpretations as to the complexity and variability of the processes. By understanding the supply chain dynamics and variability behaviour, better performance can be expected from the supply chain (e.g. lower inventories, better customer service).

Finally, it can be argued that the current Supply Chain systems are in need of a tool, which will be able to model or generate the required randomness and variability, thus providing dynamic capabilities to the planning function. And during the operational phase, what better way could there be to measure performance of a supply chain than to compare it over a period of time with a benchmark simulation model?

\section{INTRODUCTION OF A NEW SUPPLY CHAIN PLANNING METHODOLOGY}

In order to improve the performance of the supply chain the following methodology was developed, incorporating newly developed simulation components: 
- Flow Chart Stencil

- Simulation Models

- Supply Chain Template

- Supply Chain Shape Editor

- Supply Chain Case Study

- Supply Chain Input Variables

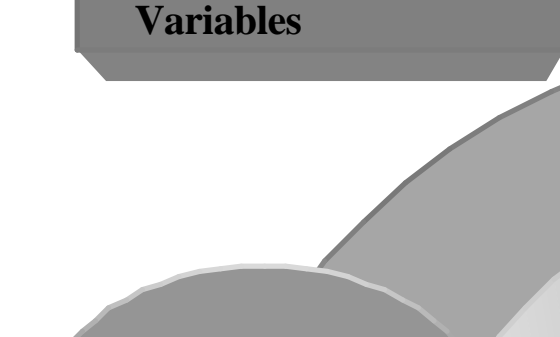

Supply Chain Design

Optimisation

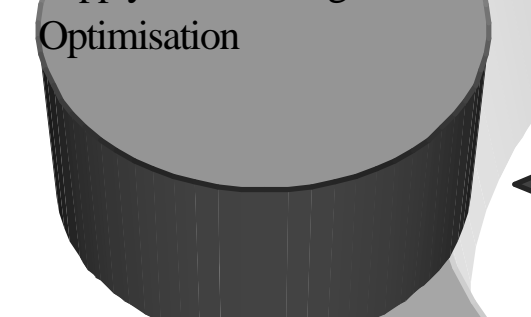

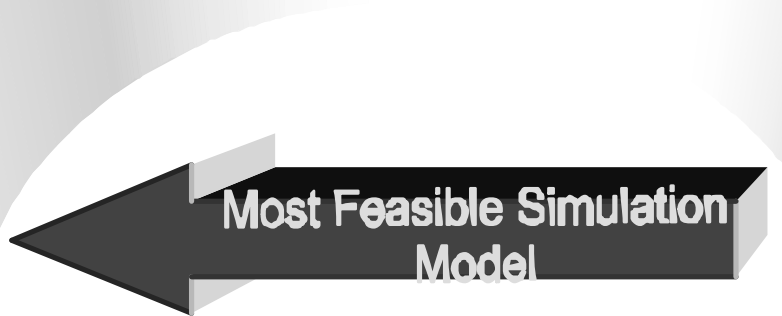

Supply Chain Design Planning
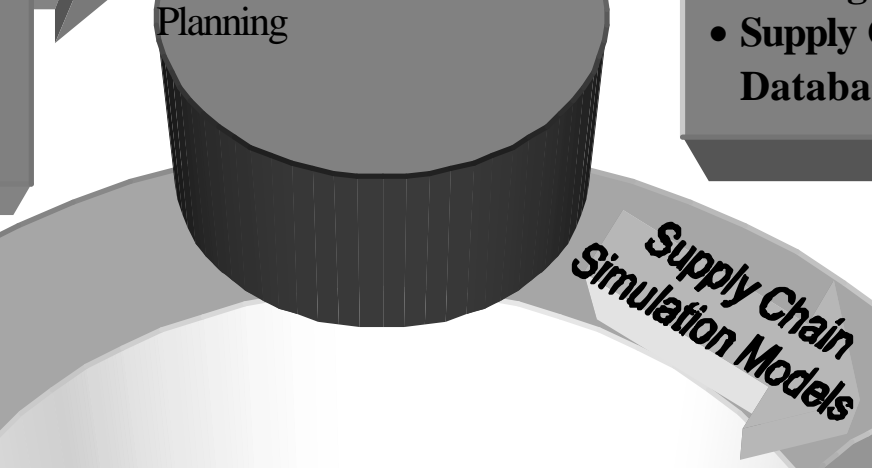

Supply Chain Design Analyses

Supply Chain Output Database

- Supply Chain Scenario Manager

- Supply Chain Reports Manager
- Supply Chain Optimiser

- Supply Chain Solver Database

Figure 2: Improved Supply Chain Planning Methodology 
This methodology was developed around four corner stones:

- Supply Chain Design Planning

- Supply Chain Design Analyses

- Supply Chain Design Optimization

- Supply Chain Operational Optimization

The round cylinder shaped containers in figure 2 represent the cornerstones. An Inner circle connects the cornerstones to symbolise the connectivity between them. The arrowhead boxes illustrate the core inputs and constructs of the cornerstones, while the arrows illustrate the information link between the cornerstones. The following paragraphs will illustrate each cornerstone in detail.

\subsection{Supply Chain Design Planning}

Supply Chain Design Planning is the first cornerstone in the methodology and this forms the foundation of the other cornerstones. In this phase the Supply Chain Planner will design or map out the entire Supply Chain Process. Figure 3 highlights the various steps within the planning phase and is followed by an explanation of the different steps.

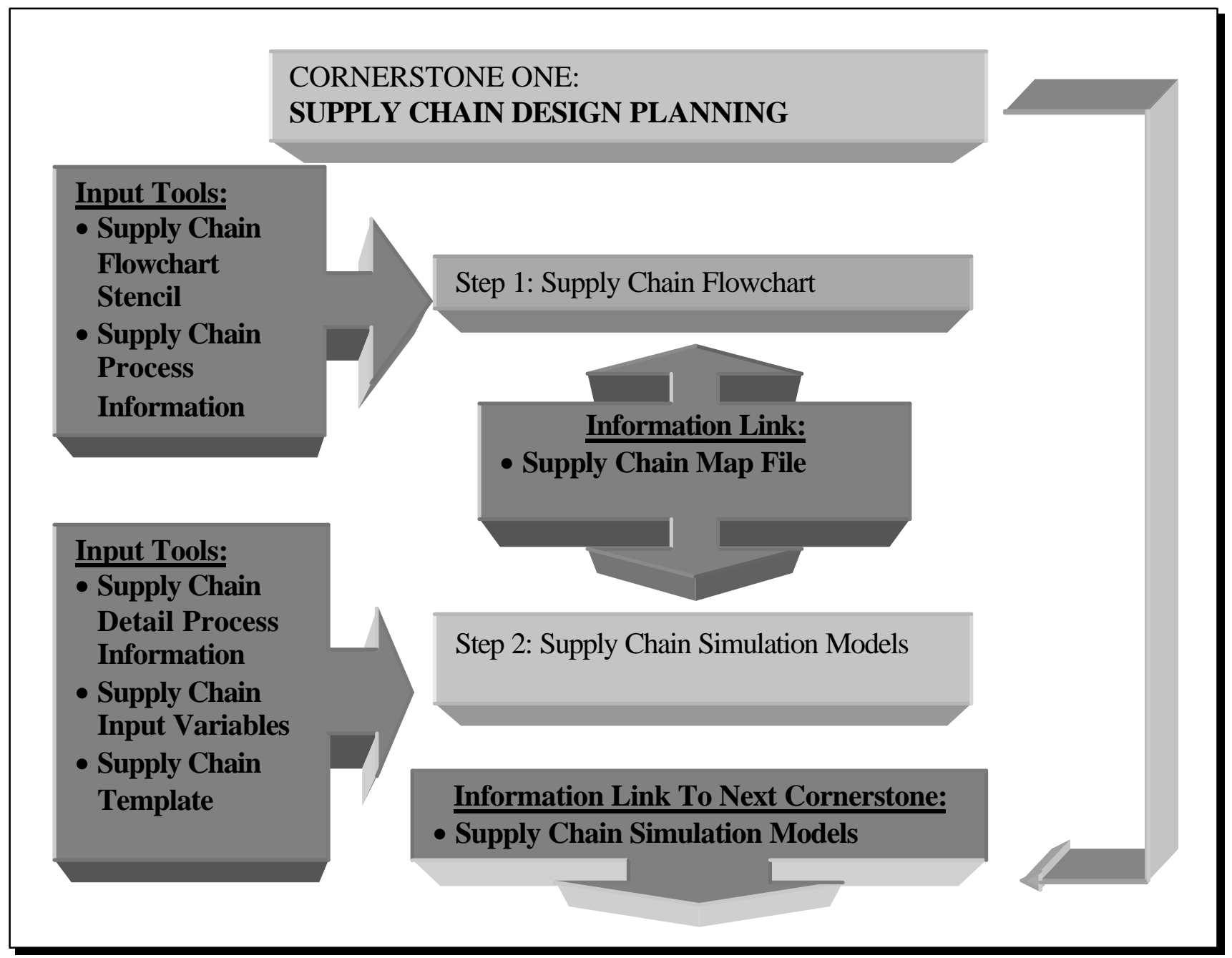

Figure 3. Cornerstone One: Supply Chain Design Planning 


\section{Step 1: Supply Chain Flow Chart}

The Supply Chain Planner will first create a high level flowchart of the appropriate Supply Chain, by using a custom designed Supply Chain Stencil within Visioß (a flowchart package from Microsoft $\left.{ }^{\circledR}\right)$. There are seven flowchart modules in the stencil:

- Batching

- Buffer

- Decision

- Location

- Operation

- Supply Plan

- Transportation

As soon as the Supply Chain Planner has finished the Supply Chain Flowchart, it can export the flowchart to Arena ${ }^{\circledR}$ by using the Process Simulation Macro. The Supply Chain Stencil only allows high-level process information and the detail process information must be changed or developed in Arena ${ }^{\circledR}$ with the Supply Chain Template. Figure 4 illustrates an example flowchart of a Supply Chain Process for a car manufacturer. The flowchart Stencils was developed with Microsoft Visioß

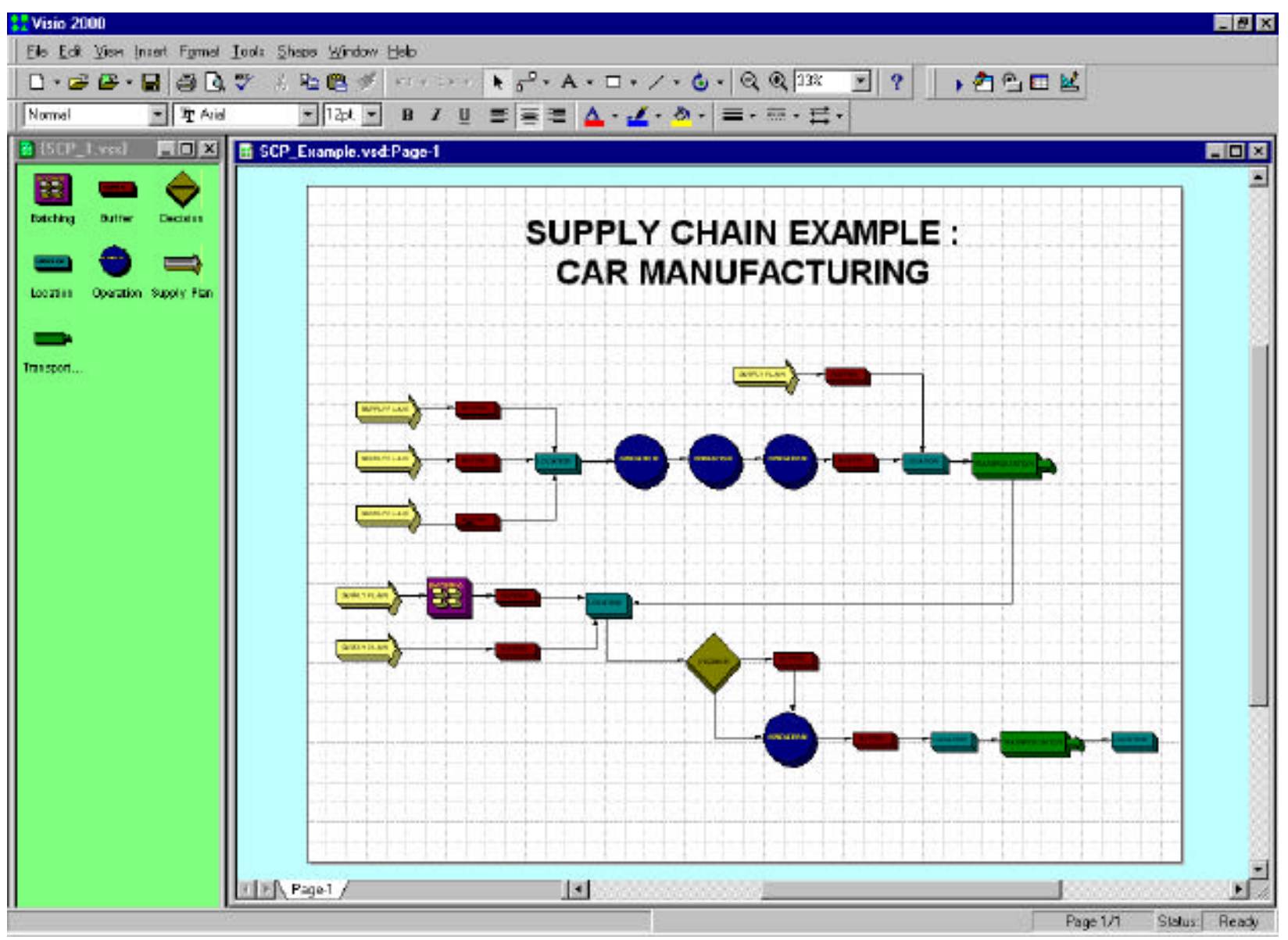

Figure 4. Flowchart example of a Supply Chain Process 


\section{Step 2: Supply Chain Simulation Models}

The next step of the Supply Chain Design Planning Cornerstone is to develop the Supply Chain Simulation Model. The Simulation Model can also be developed without the use of the Flow chart interface by using a custom designed Supply Chain Template. This template was developed with the Arena ${ }^{\circledR}$ Professional Edition. If the flowchart was used to develop the initial Supply Chain process, the Process Simulation Macro will import the flowchart into the Arena® environment.

The Supply Chain Planner can now start to configure the detailed Supply Chain Simulation Model by using the Supply Chain Template. The template consist out of the following building modules:

\begin{tabular}{|l|l|}
\hline Batching & Location \\
\hline Buffer & Moving Vehicle \\
\hline Conveyor & Operation \\
\hline Customer & Process Plan \\
\hline Decision & Resources \\
\hline Demand Plan & Simulation Replication \\
\hline Distribution Paths & Supply Chain Analyses \\
\hline Inventory Plan & Supply Plan \\
\hline Items & Transportation \\
\hline
\end{tabular}

It is clear that there are more building modules available within the template than in the Flowchart stencil. The reason for this is that the simulation environment is the heart of the planning process. The functionality's of the Supply Chain template helps the Supply Chain Planner to configure a specific Supply Chain in as much detail as possible. The Supply Chain Template and simulation model is not there to replace the Supply Chain Solver technology - it is there to aid in the initial design of the Supply Chain.

Once the Supply Chain Planner is satisfied that the Supply Chain Model is valid and rigid the Information link can be passed to the next cornerstone, namely the Supply Chain Design Analyses.

\subsection{Supply Chain Design Analyses}

Supply Chain Design Analyses is the second cornerstone in the methodology. In this phase the Supply Chain Planner will validate and test various scenarios of the Supply Chain process. Figure 5 highlights the various steps within the analyses phase.

\section{Step 1: Supply Chain Scenario Analyses}

In this phase the Supply Chain Planner will start to evaluate the various scenarios. The Process Analyser of Arena ${ }^{\circledR}$ version 5.0 is used to analyse the various scenarios. The Process Analyser uses a control/response approach in combination with a spreadsheet-style (or grid) interface; one can quickly set up your scenarios, focusing only on what's important, for easy viewing and comparison of alternatives. This allows decision-makers to easily set up and find what they are looking for - results. 
The role of the Process Analyser is to allow for comparison of the outputs from validated models based on different model inputs. Possible inputs, called controls, are variable values and resource capacity. The outputs, called responses, can be variables, or any type of Arena statistic (i.e., Dstats, Tallies, Counters, and Outputs).

The Supply Chain Planner can also create various charts of the results, including 3-D charts.

The Process Analyser has a feature that automatically identifies the scenarios that are statistically better than the others therefore allowing the Supply Chain Planner to assess the results and draw conclusions. This is a standard add-in function of Arena ${ }^{\circledR}$ Simulation Software.

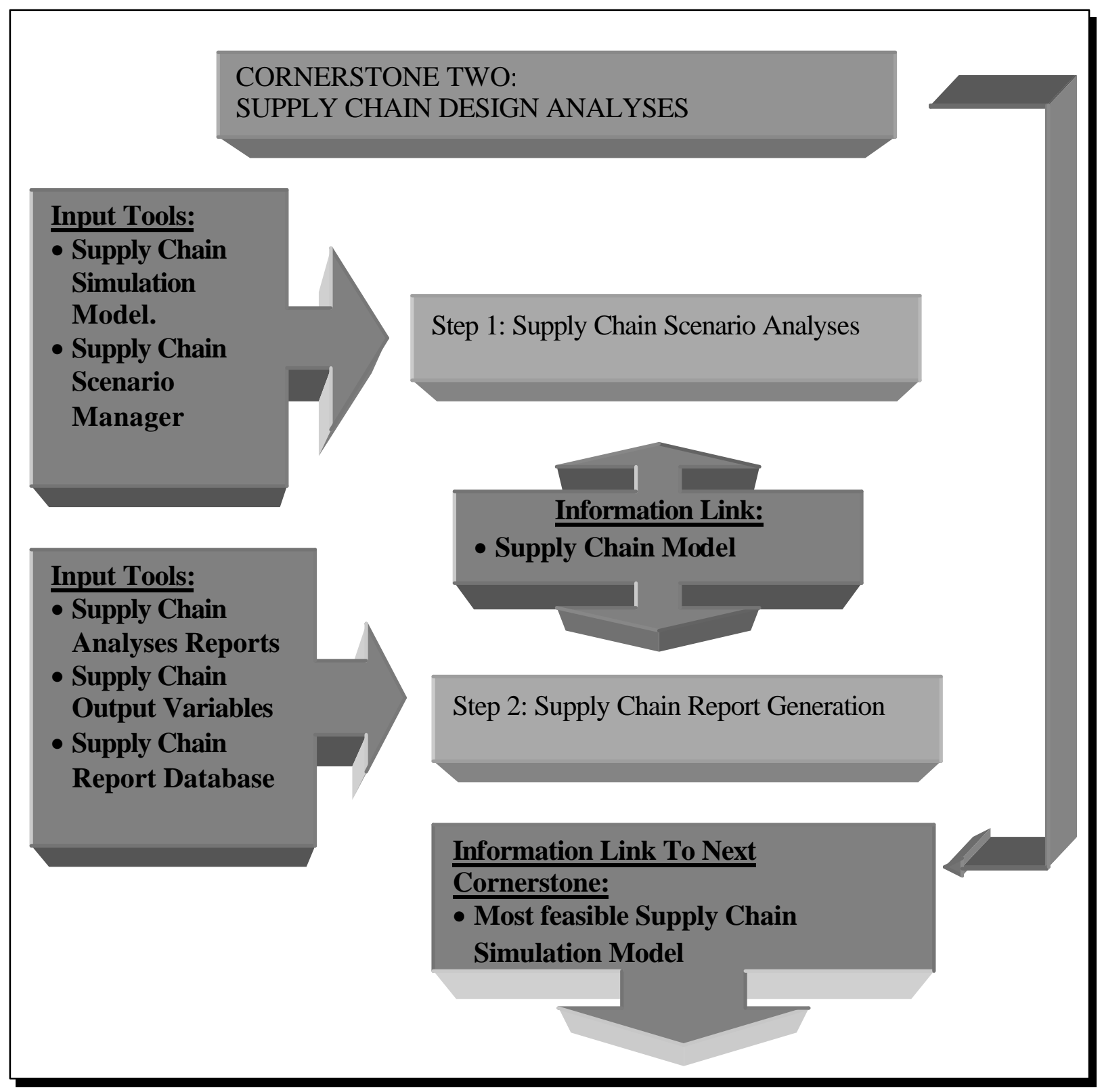

Figure 5. Cornerstone Two: Supply Chain Design Analyses 


\section{Step 2: Supply Chain Reports Generation}

The Supply Chain Planner needs to have customised reports in order to speed up the analyses phase and therefore Excel from Microsoft ${ }^{\circledR}$ is used as the Supply Chain Reports generator. The generator uses the outputs of the Simulation Model and generates customised charts and tables. Figure 6 illustrates an example of an output chart.

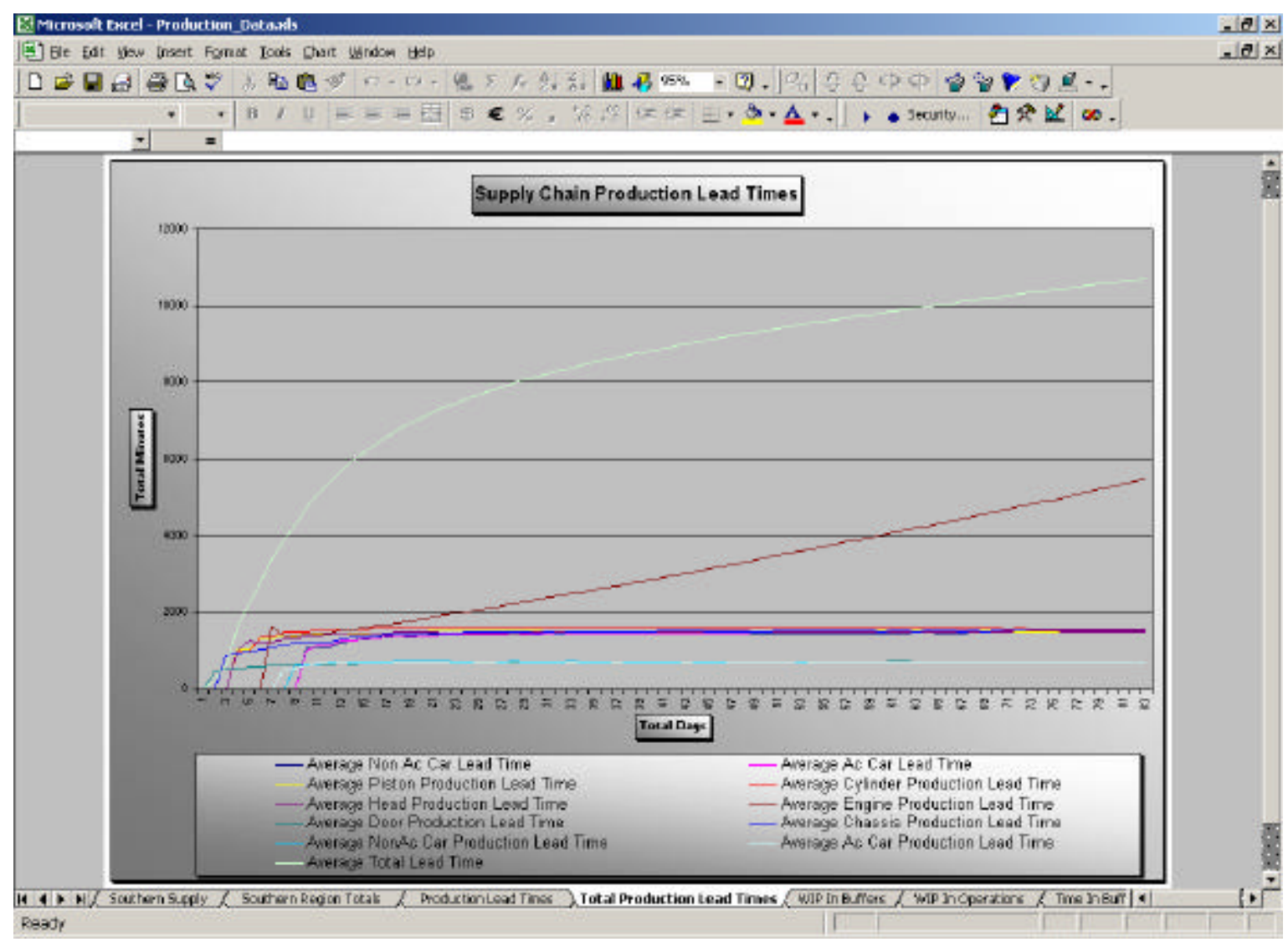

Figure 6. Customised Output Chart from the Supply Chain Reports Generator

Once the Supply Chain Planner is satisfied with the results the most feasible solution can be passed to the Supply Chain Design Optimisation phase.

The results will allow the Supply chain analyst to demonstrate, predict and measure the supply chain performance - specifically the effectiveness and efficiency of new supply chain strategies. It will also allow the analyst to test-drive new business rules and scenarios in a controlled (simulated) environment under varying conditions and decision criteria before implementation on "live" operations or customers. The business value of this approach includes the following:

- Avoid costly mistakes by making decisions based on gut feel or static modeling.

- Test in realistic conditions before implementing on live operations or customers.

- Expose the true effect of randomness and variability.

- Reveal value and eliminate wasteful bottlenecks in existing processes. 
- Test drive new business rules.

- Validate investment allocations.

- Demonstrate the impact of change to others.

- Enforce change with confidence.

\subsection{Supply Chain Design Optimisation}

Supply Chain Design Optimisation is the third cornerstone in the methodology. In this phase the Supply Chain Planner will optimise the most feasible Supply Chain Simulation Model by means of Optquest ${ }^{\circledR}$ for Arena ${ }^{\circledR}$.

Figure 7 highlights the various steps within the optimisation phase.

\section{Step 1: Supply Chain Control Selection}

In this phase the Supply Chain Planner will start to optimise the most feasible Supply Chain Model. Optquest ${ }^{\circledR}$ for Arena ${ }^{\circledR}$ is used for the optimisation.

In today's highly competitive global environment, Supply Chain Planners are faced with many difficult decisions, such as allocating financial resources, building facilities, managing inventories, determining product mix strategies, and more. Modelling a Supply Chain problem by means of the Supply Chain Template will tell the Supply Chain Planner what performance measures can be expected by using a certain strategy.

A strategy can be defined as a certain set of values for the controls. In other words a strategy includes a scenario and solution. Note that "solution" refers to the control values (inputs to the Supply Chain Simulation Model), not to the resulting values of the performance measures (responses, or outputs from the Supply Chain Simulation Model).

The controls can be Variables or Resources in the Supply Chain Model. After the definition of the controls in the Supply Chain Simulation Model, a selection can be made of which controls to optimise in OptQuest ${ }^{\circledR}$. The values of these controls will change with each simulation until OptQuest ${ }^{\circledR}$ finds values that yield the best objective. For some analyses, it might be better to fix the values of certain controls and optimise the rest.

\section{Step 2: Supply Chain Constraints}

The next step is to define the Supply Chain Constraints. These Constraints restrict the controls by defining relationships among them. For example, if the total budget for scanners (R20,000 each) and printers (R10,000 each) is R50,000, you can define this as:

$20000 *$ scanners $+10000 *$ printers $<=50000$

Supply Chain Constraints can narrow the search for the optimal solution, thus improving OptQuest's performance. Solutions that violate a constraint are constraint-infeasible; OptQuest ${ }^{\circledR}$ does not send them to Arena ${ }^{\circledR}$ for evaluation. 
Input Tools:

- Supply Chain Simulation Model.

- Supply Chain Optimizer

- Variables or Resources.

Step 1: Supply Chain Control Selection

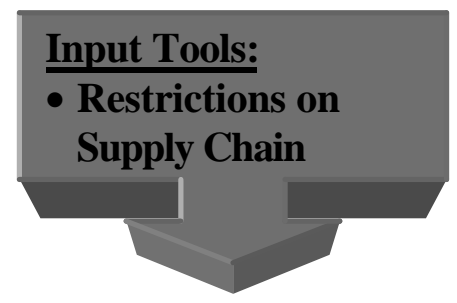

Step 2: Supply Chain Constraints

Step 3: Supply Chain Objective \& Requirements

Step 4: Update Supply Chain Solver Database

Information Link To Next Cornerstone:

- Supply Chain Solver Database

Figure 7. Cornerstone Three: Supply Chain Design Optimisation 


\section{Step 3: Supply Chain Objective Requirements}

The next step is to define the Supply Chain Objective and requirements. The following paragraphs explain the meaning of an objective and requirement.

An objective can be defined as a response in the Arena model that represents the model's objective function. Requirements are restrictions on the values of responses. These differ from constraints, since constraints restrict controls. When you define a requirement, you give it an upper bound, a lower bound, or both (a range). Like constraints, requirements must be satisfied for a solution to be considered feasible.

A feasible solution is one that satisfies all constraints and requirements. Each time OptQuest ${ }^{\circledR}$ generates a new set of values for the Supply Chain Controls, it tests the solution for Supply Chain Constraint feasibility. Only constraint-feasible solutions are sent to Arena ${ }^{\circledR}$ for evaluation. OptQuest ${ }^{\circledR}$ then uses the responses from Arena to determine if an evaluated solution is requirement-feasible.

After solving an optimisation problem with OptQuest ${ }^{\circledR}$ the Supply Chain Planner will run a sensitivity analysis to determine the robustness of the results. The sensitivity analysis is a report that assesses the sensitivity of the objective function value to changes in the values of the controls. It does this by compiling solutions that are within a specified percentage of the best solution and then calculating statistics for the control values of those solutions.

\section{$>\quad$ Step 4: Update Supply Chain Solver Database}

Once the Supply Chain Planner is satisfied with the results of the optimised solution, the results can be transferred to the Supply Chain Solver Database. The Supply Chain Solver Database is used as the input for the next cornerstone, the Supply Chain Operational Optimisation.

\subsection{Supply Chain Operational Optimisation}

Supply Chain Operational Optimisation is the fourth cornerstone in the methodology. In this phase the Supply Chain Planner will use the Supply Chain Solver Database as the input for the Supply Chain Solver Technology. Figure 8 highlights the relationships between the various tables within the Supply Chain Solver Database.

The purpose of this database is to capture all the results of the Optimised Supply Chain Simulation Solution. The results will then be used as the initial inputs in the Supply Chain Solver Technology. For example, if the Optimised Supply Chain Simulation Solution shows that the maximum capacity of a buffer is 5 units, then this value will be used as the maximum capacity for the buffer in the Solver Technology Database. 


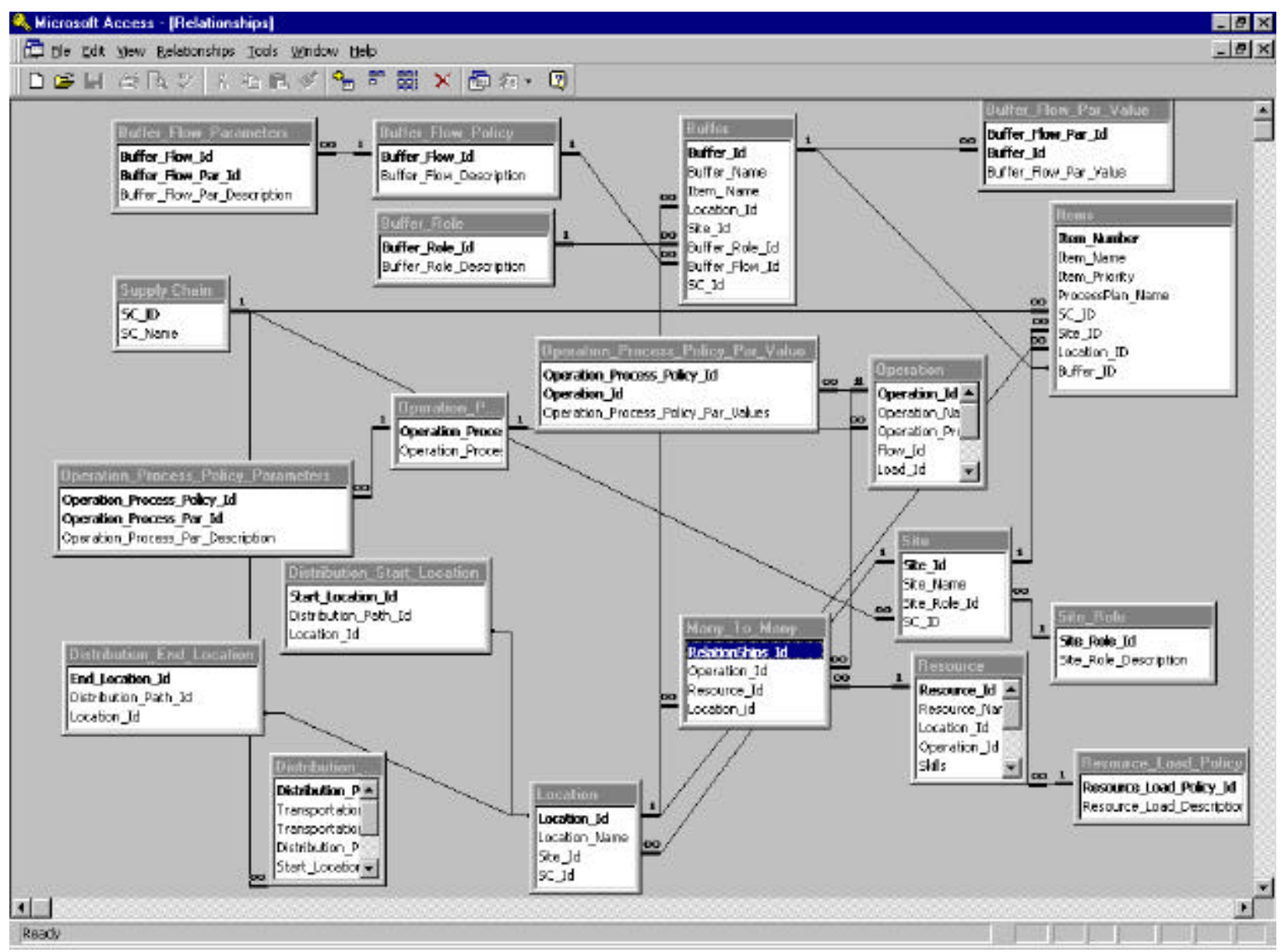

Figure 8 Supply Chain Solver Database Relationships

\section{CONCLUSION OF IMPROVED SUPPLY CHAIN PLANNING METHODOLOGY}

Supply Chain Management is complex and the key to any supply chain performance improvement is to understand the variability of the processes of the system. Because of the complexity of Supply Chain Planning companies tend to invest in Supply Chain Solution tools. Traditionally, companies have invested mainly in software or consultancy solutions for optimising their Supply Chains. Most often these solutions were derived without considering the dynamic state and variability of their Supply Chain.

Introducing this Supply Chain Planning Methodology as part of the planning process will aid and complement the Supply Chain Solution tools and its basic strength is in evaluating system variation and interdependencies.

Supply Chain Planning Methodology will usually be used to describe the current real-life system and to design a new system that has a better performance. It can therefore be used as a good benchmark to compare the actual system performance with. The methodology predicts the effect of changes to supply chain policies, such as replenishment, warehousing, transportation, and production strategies without implementing the changes in the real-life system and having the risk of investing in solutions that are not profitable. 
When using this methodology it will force the Supply Chain Analysts to re-evaluate their way of thinking, and their understanding of Supply Chain Operations. It will further help to define the Supply Chain more clearly and it can also minimise the margin of error.

This methodology can help organisations to understand and gain knowledge of the Supply Chain dynamics by making better evaluations (test-drive or perform "what-if" analyses) of the supply chain in order to improve the performance, both from a cost and customer satisfaction perspective.

\section{REFERENCES}

[1] Shaw, A.W. 1915. "Some Problems in Market Distribution", Harvard University Press.

[2] Christopher, M. 1999. Logistics and Supply Chain Management, Pittan Publishing, 1992AMR Research.

[3] Archibald, G. 1999. "Supply chain vs supply chain: using simulation to compete beyond four walls", Winter Simulation Conference.

[4] Houlihan, J.B. 1988. International Supply Chain Management, Manufacturing Issues, Booz, Allen and Hamilton.

[5] Gartner Group. March 2002. Supply Chain Magic Quadrant Update, Sales Configuration Vendors: 1H02 Magic Quadrant.

[6] Matwijec, T. 1999. "Using Simulation in Supply Chain Management", Systems Modeling Corporation.

[7] Kelton W.D., Sadowski R.P. and Sadowski D.A., 1998. Simulation with Arena.

\section{Other relevant sources}

[8] Senge P.M. 1990. "The Fifth Discipline: The Art and Practice of learning Organisations", Doubley, NY.

[9] Buxton K. 1998. "Supply Chain Simulation: Staying Competitive", Systems Modeling Corporation.

[10] Payne T. 2000. "Simulating the Supply Chain", European Supply Chain Manager, 3M.

[11] Ingalls R.G. "The Value of Simulation in Modeling Supply Chains", Manufacturing Strategy Group, Compaq.

[12] Wyland B. January 2000. "Simulating the Supply Chain", IIE Solutions.

[13] Chase R.B. and Aquilano N.J. 1995. Production And Operations Management: Manufacturing Services, 7 th edition.

[14] Bowersox D.J. and Closs D.J. 1996. Logistical Management: the integrated supply chain process, McGraw-Hill, USA.

[15] www.gartnergroup.com

[16] www.supply-chain.org 